\title{
Endothelial lipase provides an alternative pathway for FFA uptake in lipoprotein lipase-deficient mouse adipose tissue
}

\author{
Dagmar Kratky, ${ }^{1,2}$ Robert Zimmermann, ${ }^{1}$ Elke M. Wagner, ${ }^{1}$ Juliane G. Strauss, ${ }^{1}$ Weijun Jin, ${ }^{3}$ \\ Gerhard M. Kostner, ${ }^{2}$ Guenter Haemmerle,, ${ }^{1}$ Daniel J. Rader, ${ }^{3}$ and Rudolf Zechner ${ }^{1}$ \\ ${ }^{1}$ Institute of Molecular Biosciences, University of Graz, Graz, Austria. 2Institute of Molecular Biology and Biochemistry, Center of Molecular Medicine, \\ Medical University of Graz, Graz, Austria. ${ }^{3}$ School of Medicine, University of Pennsylvania, Philadelphia, Pennsylvania, USA.
}

\begin{abstract}
Lipoprotein lipase (LPL) is thought to be the only enzyme responsible for the catabolism of triglycerides (TGs) associated with TG-rich lipoproteins in adipose tissue (AT). However, LPL deficiency in humans and induced mutant mice is not associated with decreased fat mass. We investigated whether endothelial lipase (EL), a recently discovered phospholipase, might represent an alternative mechanism for the uptake of phospholipid-derived fatty acids in murine lipoprotein-deficient AT. When $L P L$ was expressed in AT and isolated murine adipocytes, $E L \mathrm{mRNA}$ was not detectable. In contrast, mouse AT and isolated adipocytes that lacked $L P L$ expressed large amounts of $E L$ mRNA. The cellular phospholipase activity in LPL-deficient fat pads was increased 4-fold compared with control fat pads and could be inhibited to control levels by a specific EL antibody. Fatty acids produced by EL activity were absorbed by adipocytes and incorporated into the TG moiety of AT. Our results suggest that EL activity in AT and other peripheral tissues might contribute to the tissue uptake of free fatty acids, which could have important implications for the metabolism of plasma lipoproteins.
\end{abstract}

\section{Introduction}

Lipoprotein lipase (LPL) is responsible for the generation of fatty acids from circulating triglyceride-rich (TG-rich) lipoproteins. The enzyme is predominantly found in adipose tissue (AT) and muscle, where it is bound to the capillary endothelium by its interaction with glucosaminoglycans. In AT, the released fatty acids are absorbed and reesterified, and TGs are stored within lipid droplets $(1,2)$. Complete absence of LPL, which occurs in human individuals, cats, and minks that are homozygous for mutations in the LPL gene (3-5), results in massive accumulation of plasma TGs, consistent with the view that the absence of LPL impedes the normal clearance of circulating TGs (6). In contrast to humans, cats, and minks, homozygous $L P L$-knockout mice ( $L 0$ mice) $(7,8)$ or mice that lack functional LPL due to a mutation in the cld locus (9) do not survive the suckling period and die between 18 and 24 hours after birth. However, the transient expression of LPL by adenovirus infection during the suckling period (10) or the transgenic expression of LPL exclusively in skeletal muscle (SM) (11, 12), cardiac muscle (CM) (13), or liver (14) can rescue $L 0$ mice from neonatal death.

The remarkable phenotype observed in LPL-deficient humans, mice, cats, and minks strongly supports the view that LPL is essential for the clearance of TG-associated fatty acids and their subsequent uptake by peripheral tissues. Unexpectedly, however, LPLdeficient humans or animals exhibit essentially normal AT mass, and their fat cells are filled with lipid $(4,5,12,13,15-17)$. Importantly, the FFA composition of the TG moiety in LPL-deficient AT differed markedly from that in control AT, exhibiting a drastic

Nonstandard abbreviations used: AT, adipose tissue; CM, cardiac muscle; EL, endothelial lipase; $L 0$ mice, $L P L$-knockout mice; $L 2$ mice, mice with 2 LPL wild-type alleles; LPL, lipoprotein lipase; PC, phosphatidylcholine; PL, phospholipid; SM, skeletal muscle; TG, triglyceride; THL, tetrahydrolipstatin.

Conflict of interest: The authors have declared that no conflict of interest exists.

Citation for this article: J. Clin. Invest. 115:161-167 (2005).

doi:10.1172/JCI200515972. decrease in polyunsaturated, essential fatty acids $(12,18)$. This finding suggested that preservation of AT mass in the absence of LPL was achieved by de novo biosynthesis of endogenous fatty acids. Recently we demonstrated that lipogenesis is indeed activated in LPL-deficient AT through an SREBP-1-mediated process (19). Lipogenesis, however, could not explain the presence of low levels of polyunsaturated fatty acids in LPL-deficient AT. Therefore, we speculated that alternative fatty acid uptake mechanisms must exist when LPL is absent. These mechanisms could involve the induction of alternative lipases that are capable of providing fatty acids from plasma lipoproteins and/or the uptake of FFAs from FFA/albumin complexes.

Endothelial lipase (EL) is a plausible candidate to provide FFAs for subsequent uptake in peripheral tissues in addition to LPL. The EL gene codes for an enzyme that belongs to the family of TG lipases together with LPL, hepatic lipase, and pancreatic lipase $(20,21)$. EL is expressed in many tissues and organs, such as the liver, lung, kidney, steroid hormone-producing organs, thyroid, and placenta. Additionally, EL is also expressed in vascular endothelial cells. This is a unique feature among the lipase family, because despite the fact that LPL and hepatic lipase are active on the lumenal surface of the endothelium, neither is synthesized by endothelial cells $(1,22)$. EL exhibits a $45 \%$ amino acid homology with LPL with putative heparin-binding and hydrophobic regions, which suggests that EL, like LPL and hepatic lipase, is located on the capillary endothelium (23-26). In contrast to LPL, however, EL was shown to be a phospholipase with little TG lipase activity (less than $0.1 \mu \mathrm{mol} \mathrm{FFA} / \mathrm{ml} / \mathrm{h})$ in the presence of serum $(20,21$, 27). The primary lipoprotein substrate of EL is HDL (27), and the enzyme has been assigned an important role in HDL metabolism $(26,28-30)$. Specifically, mice that lack EL have increased HDL cholesterol levels $(28,29)$, whereas EL overexpressing mice exhibited decreased HDL cholesterol levels (31). Additionally to its enzyme function as phospholipase, EL has been shown to facili- 


\section{Table 1}

LPL activity levels in AT, CM, and SM of fed mice

\begin{tabular}{lcccc} 
Genotype & $\boldsymbol{n}$ & $\begin{array}{c}\text { AT-LPL activity } \\
(\mu \mathrm{mol} \mathrm{FFA/g/h)}\end{array}$ & $\begin{array}{c}\text { CM-LPL activity } \\
(\mu \mathrm{mol} \text { FFA/g/h) }\end{array}$ & $\begin{array}{c}\text { SM-LPL activity } \\
(\mu \mathrm{mol} \text { FFA/g/h) }\end{array}$ \\
L2 & 10 & $8.6 \pm 3.1$ & $18.4 \pm 4.3$ & $2.2 \pm 0.5$ \\
LO-MCK & 7 & $0.09 \pm 0.05^{\mathrm{A}}$ & $3.7 \pm 0.8^{\mathrm{B}}$ & $7.9 \pm 2.7^{\mathrm{B}}$ \\
L2-MCK & 7 & $16.5 \pm 6.5$ & $25.8 \pm 3.9^{\mathrm{C}}$ & $7.9 \pm 2.4^{\mathrm{B}}$ \\
LO & 6 & n.d. & n.d. & n.d. \\
\hline
\end{tabular}

All values represent means $\pm S D$. Age of the animals at the time of analysis was $10-14$ weeks. ${ }^{A} P \leq 0.001,{ }^{B} P \leq 0.01,{ }^{C} P<0.05$ vs. controls (L2). n.d., not detected.

tate the cellular uptake of lipoprotein particles by a nonenzymatic mechanism similar to that of LPL or hepatic lipase $(23,25)$.

The present study was designed to investigate whether $E L$ is expressed in AT of mice that lack LPL activity in adipocytes. We show that EL expression is induced on the mRNA level and increased enzyme activities are found in LPL-deficient AT. The FFAs generated by the increased phospholipase activity are taken up by AT and incorporated into the lipid droplets.

\section{Results}

Tissue LPL activities and LPL mRNA abundance in AT. LPL enzyme activities in AT and muscle as well as LPL mRNA levels in AT for all mouse genotypes used in this study are summarized in Table 1 and Figure 1A, respectively. Normal mice with 2 LPL wild-type alleles ( $L 2$ mice) were used as control animals. $L 2-M C K$ mice are transgenic animals that overexpress a human $L P L$ minigene under the control of the muscle specific mouse-creatine kinase promoter (32). Accordingly, these animals have increased LPL activities in SM and CM, whereas LPL activity in AT is identical to control mice (Table 1). L2 and L2-MCK mice show similar LPL mRNA expression levels in AT (Figure 1A).

LO-MCK mice resulted from the cross-breeding of $L 2-M C K$ mice with heterozygous $L O$ mice (11). LO-MCK animals lacked both mouse LPL alleles but expressed the human LPL transgene. Accordingly, these animals have detectable LPL activities exclusively in SM and CM but lack enzyme activity (Table 1) and detectable mRNA levels (Figure 1A) in AT.

Finally, $L O$ mice that had been rescued from postnatal death by the transient expression of LPL during the suckling period utilizing adenovirus-mediated gene transfer were used in this study (10). Rescued adult $L 0$ mice exhibited no detectable LPL enzyme activity (Table 1) or mRNA (Figure 1A) in any tissue analyzed.

Plasma TG levels. As shown in Table 2, increased muscle LPL activities in $L 2-M C K$ mice resulted in a highly significant decrease of plasma TG levels compared with controls (56\%). Additionally, HDL cholesterol concentrations were also decreased (16\%). The physiological response to the altered tissue-specific LPL expression pattern in $L 0-M C K$ mice resulted in decreased plasma TG levels (41\%) and decreased plasma HDL concentrations (29\%). The complete loss of LPL activity in all tissues of $L O$ mice resulted in extremely high plasma TG levels (20-fold increase) and essentially undetectable plasma HDL cholesterol levels.

FFA composition of AT lipids. The variation of AT-LPL activities among the mouse genotypes resulted in marked differences in the fatty acid composition of the TG and phospholipid (PL) moieties (Table 3). Compared to AT that expressed normal LPL activities
(L2 and L2-MCK mice), AT that lacked LPL (LO-MCK mice) exhibited a highly significant reduction of $18: 2$ and 18:3 fatty acids in both the TG ( $88 \%$ and $87 \%$, respectively) and the PL $(60 \%$ and $71 \%$, respectively) moiety. Conversely, the concentrations of $16: 1$ and $18: 1$ were increased in the TGs (247\% and $57 \%$, respectively) and the PL ( $174 \%$ and $33 \%$, respectively) content.

EL $m R N A$ expression in AT and liver. Northern blot analysis (Figure 1B) revealed that no $E L$-specific $m R N A$ was found in AT of control (L2) and $L 2-M C K$ mice. In contrast, high levels of mouse EL mRNA were detected in AT that lacked LPL activity. Compared with L2 and $L 2-M C K$ mice, both $L O-M C K$ mice and rescued adult $L O$ mice showed increased EL mRNA levels, which indicates that the induction of AT-EL expression was not affected by the expression of LPL in other tissues but solely by the absence of LPL in adipocytes. Similarly to what is shown here, an induction of $E L$ mRNA expression was also found in AT of mice that expressed LPL exclusively in CM (13) (data not shown). The upregulation of EL mRNA expression in AT of LO-MCK mice was additionally confirmed by quantitative real-time PCR and revealed a 7.9-fold induction compared with control adipose tissue (Figure 1C).

Hepatic EL mRNA concentrations were found to be similar in $L 2$ and LO-MCK mice by real-time PCR (Figure 2) and in Northern blot experiments (Figure 2, inset). Interestingly, EL mRNA concentrations were markedly higher (2-fold) in LPL-deficient AT than in liver samples independent of the mRNA quantitation method.
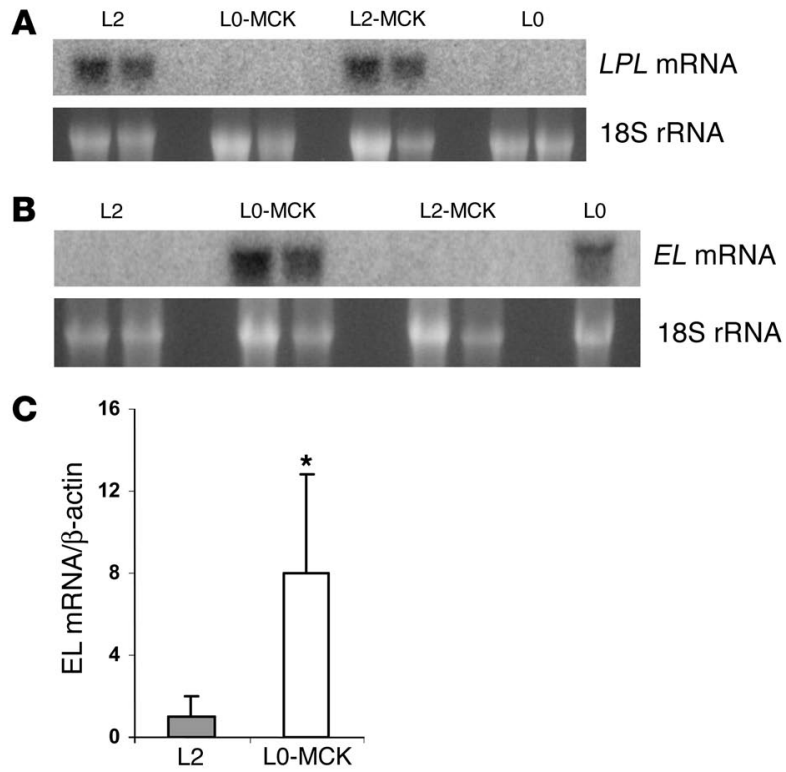

\section{Figure 1}

Murine $L P L$ and $E L$ mRNA expression in adipose tissue. Relative abundance of (A) $L P L$ and (B) EL mRNA in AT of mice expressing ( $L 2$, $L 2-M C K)$ or lacking $(L O-M C K, L O) L P L$ in AT. Total RNA was isolated from murine AT in the absence or presence of LPL and subjected to Northern blot analysis. Ten micrograms of total RNA were separated on a formaldehyde/agarose gel, blotted onto a nylon membrane, and hybridized with a murine-specific [32P]-labeled cDNA probe. rRNA, ribosomal RNA. (C) EL mRNA concentrations in AT were confirmed by fluorescent real-time PCR (see Methods). EL mRNA quantities were normalized to those of $\beta$-actin. Data are expressed as the mean values of 3 experiments performed in duplicates relative to the expression of $E L$ mRNA in control mice (L2). Bars represent mean $\pm \mathrm{SD}$ of the hybridization intensity signals. ${ }^{*} P<0.05$. 


\section{Table 2}

TG and HDL cholesterol plasma levels

\begin{tabular}{llcc} 
Genotype & $\boldsymbol{n}$ & TGs $(\mathbf{m g} / \mathbf{d l})$ & HDL-C (mg/dl) \\
L2 & 9 & $98 \pm 27$ & $107 \pm 16$ \\
LO-MCK & 9 & $58 \pm 8^{\mathrm{A}}$ & $76 \pm 15^{\mathrm{B}}$ \\
L2-MCK & 9 & $43 \pm 10^{\mathrm{B}}$ & $90 \pm 12^{\mathrm{C}}$ \\
LO & 5 & $2,007 \pm 375^{\mathrm{B}}$ & $2 \pm 0.6^{\mathrm{B}}$ \\
\hline
\end{tabular}

All values represent mean $\pm S D$. The age of animals at the time of analysis was 9 weeks. ${ }^{A} P \leq 0.01,{ }^{B} P \leq 0.001,{ }^{C} P<0.05$ vs. controls (L2).

EL mRNA in differentiated 3T3-L1 cells and isolated mouse adipocytes. Next, we investigated whether the transcriptional activation of $E L$ gene expression might occur during the differentiation of 3T3-L1 mouse embryonic fibroblasts into adipocytes similarly as observed for LPL. Total RNA from 3T3-L1 cells at different stages of differentiation was isolated, and EL mRNA concentrations were determined by real-time PCR analysis. In contrast to LPL mRNA expression, which was markedly induced within the initial phase of differentiation (Figure 3A), EL was not expressed in undifferentiated cells or cells at 4 and 8 days of differentiation (Figure 3B). To elucidate whether isolated adipocytes express $E L$ mRNA, epididymal fat pads from AT of control and LO-MCK mice were digested by collagenase treatment, and fat cells were isolated by flotation. This procedure enabled the separation of adipocytes from other contaminating cell types such as endothelial and blood cells. Quantitative real-time PCR analysis revealed a 26-fold induction of EL mRNA expression in isolated adipocytes of $L O-M C K$ mice (Figure 3B). Thus, in the absence of LPL, isolated adipocytes are capable of synthesizing EL mRNA.

Phospholipase activity levels in LPL-deficient AT. Consistent with the increased mRNA levels, the phospholipase activity was also 4.0-fold higher in fat pads isolated from $L O-M C K$ mice as compared with $L 2$ mice (Figure 4). Preincubation of fat pads with a specific EL antiIgG totally inhibited EL activity in LO-MCK AT, which resulted in decreased phospholipase activity levels and displayed levels similar to those in $L 2$ mice. In contrast, the total phospholipase activities in preheparin or postheparin plasma of control and LO-MCK mice revealed no significant differences in the 2 genotypes ( 0.8 and 0.7 $\mu \mathrm{mol} \mathrm{FFA} / \mathrm{ml} / \mathrm{h}$, respectively).

Incorporation of PL-derived fatty acids into the TG moiety of LPL-deficient AT. The increased EL activity in LPL-deficient AT suggested a potential mechanism for the cellular uptake of FFAs and their subsequent intracellular reesterification and storage. To test this hypothesis, we incubated isolated epididymal fat pads of $L 2$ and LO-MCK animals with $\left[{ }^{14} \mathrm{C}\right]$ phosphatidylcholine-labeled $\left(\left[{ }^{14} \mathrm{C}\right] \mathrm{PC}\right.$ labeled) HDL, and the incorporation of the fatty acid-associated radioactivity into TG was examined. As shown in Figure 5, the amount of PC-derived FFAs absorbed by AT and incorporated into TGs was 4.3-fold higher in AT-LPL-deficient adipocytes than in control cells. Preincubation of fat pads with EL anti-IgG completely prevented the incorporation of PC-derived FFAs into TGs of LO-MCK fat pads. The addition of tetrahydrolipstatin (THL), an enzyme inhibitor of both EL and LPL, reduced the incorporation of $\left[{ }^{14} \mathrm{C}\right]$ FFAs in fat pads of LO-MCK mice by $75 \%$ compared with controls. Furthermore, preincubation of fat pads with $2 \mathrm{U} / \mathrm{ml}$ heparin, which releases both LPL and EL from the cell surface, also reduced the amount of $\left[{ }^{14} \mathrm{C}\right]$ FFAs in the TG fraction of LPL-deficient AT. Finally, the concerted action of both - THL and heparin - reduced the ability of LPL-deficient adipocytes to take up PC-derived FFAs and incorporate them into the TG moiety to control levels.

Incorporation of FFAs into the TG moiety of LPL-deficient AT. It is conceivable that adipose tissue lacking LPL not only induces $E L$ expression as a compensatory uptake mechanism of fatty acids but also increases the uptake of albumin-bound unesterified fatty acids. To investigate this premise, we incubated isolated epididymal fat pads of $L 2$ and $L O-M C K$ animals with $\left[{ }^{3} \mathrm{H}\right]$ oleate, and the incorporation of the fatty acid-associated radioactivity into TGs was examined. As shown in Figure 6, the amount of FFAs absorbed by AT and incorporated into TGs was 2.8-fold higher in AT-LPL-deficient adipocytes than in control cells.

\section{Discussion}

Lipases are essential for the generation of lipid-derived fatty acids and their subsequent tissue uptake. In peripheral tissues such as AT, LPL is considered the only enzyme capable of this function. Yet LPL deficiency, as observed in patients with type I hyperlipoproteinemia or in $\mathrm{LO}$ mice, is not associated with a complete absence of polyunsaturated fatty acids in AT. In fact, a significant proportion of essential fatty acids (10-30\% of normal) are still found in the lipid moiety of LPL-deficient AT, which suggests that in the absence of LPL, uptake mechanisms for plasma fatty acids must exist. Two processes are conceivable. First, FFAs could be absorbed from plasma FFA/albumin complexes, and indeed our results demonstrate that LPL-deficient AT absorbs unesterified fatty acids more efficiently than normal LPL-expressing AT. Second, alternative lipases might become activated and generate fatty acids from lipids, which are subsequently taken up by the target tissue. Considering the potential involvement of alternative lipases, we analyzed LPL-deficient AT for the expression of EL and compared it to AT from normal control mice. EL seemed a reasonable candidate because it is structurally closely related to LPL and, similar to LPL, it is found at the capillary endothelium bound to glycosaminoglycans $(23,25,26)$. Unlike LPL, however, EL hydrolyzes predominantly PLs, and the major lipoprotein substrates are not TG-rich lipoproteins but $\operatorname{HDL}(21,27)$. The enzyme is expressed in endothelial cells and a variety of other cell types and tissues. However, expression of EL in AT or muscle, the major sites of $L P L$ expression, has not been reported.

When fat tissue was analyzed for EL mRNA in Northern blot experiments, large amounts of EL mRNA were found in AT that lacked LPL, whereas no EL mRNA was detected in $L P L$-expressing

\section{Table 3}

Fatty acid composition of PLs and TGs in AT of control (L2) and AT-LPL-deficient (LO-MCK) mice

\begin{tabular}{|c|c|c|c|c|}
\hline \multirow{3}{*}{$\begin{array}{l}\text { Fatty } \\
\text { acid }\end{array}$} & \multicolumn{4}{|c|}{ Fatty acid composition (\%) } \\
\hline & \multicolumn{2}{|c|}{ PLs } & \multicolumn{2}{|c|}{ TGs } \\
\hline & $L 2$ & LO-MCK & $L 2$ & LO-MCK \\
\hline $16: 0$ & $17.00 \pm 2.24$ & $17.47 \pm 1.71$ & $19.92 \pm 1.49$ & $27.40 \pm 1.98^{\mathrm{A}}$ \\
\hline $16: 1$ & $3.00 \pm 0.13$ & $8.22 \pm 2.33^{A}$ & $6.67 \pm 2.15$ & $23.20 \pm 3.68^{B}$ \\
\hline $18: 0$ & $17.33 \pm 2.17$ & $14.48 \pm 3.37$ & $2.51 \pm 0.20$ & $3.15 \pm 0.21$ \\
\hline $18: 1$ & $31.15 \pm 4.10$ & $41.32 \pm 3.34^{A}$ & $22.90 \pm 3.98$ & $35.90 \pm 3.11^{\mathrm{A}}$ \\
\hline $18: 2$ & $18.76 \pm 1.03$ & $7.50 \pm 0.97^{\mathrm{B}}$ & $40.34 \pm 2.52$ & $4.85 \pm 0.21^{B}$ \\
\hline $18: 3$ & $2.31 \pm 1.10$ & $0.68 \pm 0.39 c$ & $2.17 \pm 0.18$ & $0.28 \pm 0.20^{c}$ \\
\hline
\end{tabular}

Data from 4 mice are shown as mean \pm SD. ${ }^{A} P \leq 0.01$; ${ }^{B} P \leq 0.001$,

${ }^{c} P<0.05$ vs. controls (L2). 


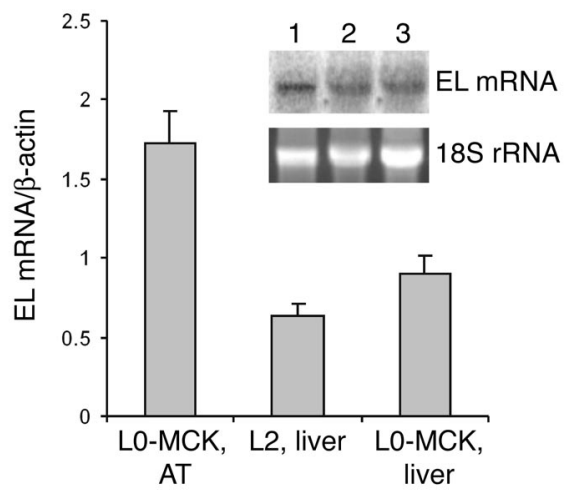

Figure 2

Murine $E L$ mRNA expression in liver. Relative abundance of $E L$ mRNA in livers in the presence (L2) or absence ( $L O-M C K)$ of AT-LPL were compared with EL expression in AT of $L O-M C K$ mice. Total RNA was isolated from fat pads of fed $L 2$ and $L O-M C K$ mice. mRNA concentrations were determined by fluorescent real-time PCR. EL mRNA quantities were normalized to those of $\beta$-actin. Data are expressed as the mean values of 3 experiments performed in duplicate. Bars represent mean \pm SD of the hybridization intensity signals. Inset: Representative Northern blot analysis of $10 \mu \mathrm{g}$ total RNA per lane, hybridized with a murine-specific [ $\left.{ }^{32} \mathrm{P}\right]$-labeled EL CDNA probe. Lane 1, LO-MCK AT; lane 2, L2 liver; lane 3, LO-MCK liver.

control AT. The induction of EL expression was observed in LPLdeficient AT of mouse lines that lacked LPL completely $(L O)$ or expressed LPL exclusively in SM (LO-MCK) or CM (data not shown), which suggests that the location and the quantity of LPL expression in other tissues of the body do not affect EL expression in AT. The comparison of the signal intensities determined by quantitative real-time PCR indicated that higher relative amounts of $E L$ mRNA were present in LPL-deficient AT than in liver, an organ of high $E L$ abundance. This observation made it likely that $E L$ mRNA was actually produced by the adipocytes in AT rather than by contaminating endothelial cells. To test this hypothesis experimentally, we treated fat pads from control and LPL-deficient AT with collagenase, isolated adipocytes by standard techniques, and analyzed total RNA for EL mRNA levels by quantitative real-time PCR. As expected, isolated adipocytes from LPL-deficient AT produced high amounts of EL mRNA, whereas no signals were detected in RNA derived from control AT. In differentiated 3T3-L1 cells, which express high amounts of LPL during the course of differentiation, EL mRNA was undetectable at all time points of the differentiation period. These findings are consistent with the observations in AT. It follows that the absence of LPL is a prerequisite for expression of $E L$. Our findings indicate that adipocytes induce the transcription of the otherwise dormant EL gene when LPL is absent. Interestingly, the opposite scenario - namely increased $L P L$ mRNA expression in SM in the absence of EL - has been recently observed in $E L$-knockout mice (29). These findings suggest that $L P L$ and $E L$ expression are reciprocally regulated in a coordinate manner. The signals and mechanisms involved in these processes are not known. One could only speculate that the reduced import of fatty acids and particularly essential fatty acids is sensed by fatty acid-activated transcription factors such as SREBP-1c or PPAR $\gamma$, which in turn affect LPL or EL transcription.

Increased EL mRNA levels in LPL-deficient AT were associated with increased phospholipase activity in LPL-deficient fat pads and isolated adipocytes, consistent with the original reports that EL acts as a phospholipase $(20,21)$. Additionally, when fat pads were incubated with $\left[{ }^{14} \mathrm{C}\right] \mathrm{PC}$-labeled HDL as substrate, AT-EL was shown to catabolize HDL PLs. The released fatty acids were taken up by the fat cells and subsequently incorporated into the TG droplets. Three independent lines of evidence proved that this process was mediated by EL. First, anti-EL IgG inhibition of EL abolished the incorporation of PC-derived fatty acids into the TG moiety of LO-MCK fat pads. Second, the addition of the nonspecific lipase inhibitor THL to $L 0-M C K$ fat pads also resulted in a marked decrease of PC-derived fatty acid incorporation into TGs compared with untreated cells. Third, the presence of heparin in the assay also resulted in decreased FFA incorporation into LPLdeficient AT-TG. These results are consistent with the assumption that EL, like LPL, is bound to the cell surface by heparansulfate proteoglycans and that EL association with the cell membrane is a prerequisite for the uptake and reesterification of fatty acids released from HDL-associated PC.

EL enzyme activity is inversely correlated to plasma HDL cholesterol levels (21). Recent studies have also shown that the inhibition of EL causes increased plasma HDL cholesterol concentrations in vivo identifying EL as important drug target for the treatment of patients with low HDL cholesterol levels $(28,31)$. Whether AT-specific EL expression in LPL-deficient mice affects plasma HDL levels is presently unknown and remains to be determined. Additionally, it will be important to clarify whether patients affected with familial LPL deficiency express EL in AT and whether EL expression contributes to the excessively low HDL cholesterol levels in these patients.
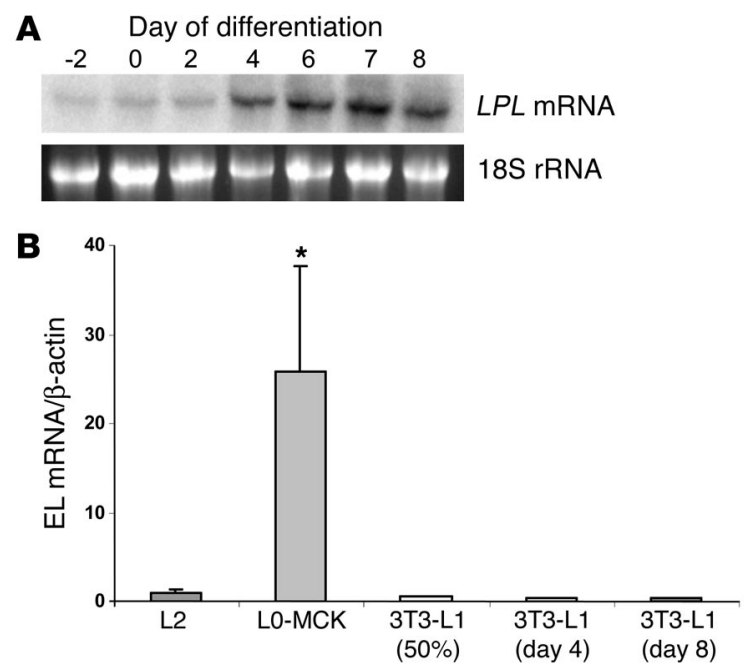

\section{Figure 3}

LPL and EL mRNA expression in differentiated 3T3-L1 cells and isolated mouse adipocytes. Fat pads of mice in the presence (L2) or absence $(L O-M C K)$ of LPL were homogenized and subjected to collagenase A digestion, and total RNA of adipocytes was isolated. Total RNA from 3T3-L1 fibroblasts was isolated at $50 \%$ cell confluence (day -2), at confluence (day 0) and during (days 2, 4, 6, and 7), and at the end of differentiation (day 8) to adipocytes. (A) Northern blot analysis of $10 \mu \mathrm{g}$ total RNA per lane, hybridized with a murinespecific [32P]-labeled LPL probe. (B) EL mRNA concentrations were determined by fluorescent real-time PCR. EL mRNA quantities were normalized to those of $\beta$-actin, and control values from $L 2$ mice were arbitrarily set to $1 .{ }^{*} P<0.05$. 


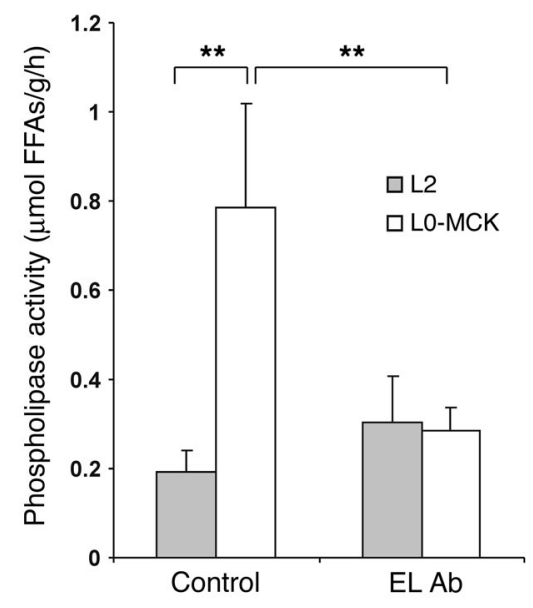

Figure 4

Phospholipase activity in murine fat pads. Fat pads of mice in the presence (L2) or absence (LO-MCK) of LPL were incubated in $250 \mu \mathrm{l}$ $\mathrm{DMEM} / 2 \% \mathrm{BSA}$ and $2 \mathrm{U} / \mathrm{ml}$ heparin for 1 hour at $37^{\circ} \mathrm{C}$. Phospholipase activity was measured by incubating the preconditioned medium with $\left[{ }^{14} \mathrm{C}\right] \mathrm{PC}$ in the absence (control) or presence (EL Ab) of $50 \mu \mathrm{g}$ anti-EL $\mathrm{lgG}$. Results are mean \pm SD from 5 mice of each genotype performed in duplicate. ${ }^{\star \star} P \leq 0.01$.

Taken together, our data are consistent with the concept that peripheral EL expression on the mRNA level and the level of enzyme activity can be initiated in murine AT when LPL is absent. In LPL-deficient AT, both the metabolic switch from the catabolism of chylomicron and VLDL TGs (which is LPL mediated) to HDL PLs (which is EL mediated) and the observed increased uptake of albumin-bound fatty acids are likely to supply those essential fatty acids that are needed to maintain essential adipocyte functions, such as accurate membrane fluidity and the biosynthesis of prostaglandins and leukotrienes. However, the markedly reduced content of polyunsaturated fatty acids in both the TG and the PL moieties of LPL-deficient AT indicated that the ELmediated FFA import and the increased uptake of albumin-bound fatty acids are not sufficient to completely normalize fatty acid import in adipocytes when LPL is absent. This deficit is additionally counteracted by the massive induction of lipogenic processes in LPL-deficient AT (19). Whether EL expression in AT has important implications for the cellular lipid metabolism and the metabolism of plasma lipoproteins remains to be elucidated. In this context, it will be important to reveal conditions other than LPL deficiency that can modulate EL expression in AT and possibly other peripheral tissues.

\section{Methods}

Mice. The generation of all mouse lines used as well as their detailed characterization was published previously (10-12). Genotypes were identified from tail tip DNA by PCR analysis, as reported (12). All animals were maintained on a regular light-dark cycle (14 h light, $10 \mathrm{~h}$ dark) and kept on a standard laboratory chow diet. All animal experiments were performed in accordance with the standards established by the Austrian Federal Ministry of Education, Science and Culture, Division of Genetic Engineering and Animal Experiments (Vienna, Austria).

Cell culture. 3T3-L1 mouse embryonic fibroblasts were cultured in DMEM containing 10\% FCS, 1\% L-glutamine, and 1\% streptomycin/penicillin at $37^{\circ} \mathrm{C}$ under $5 \%$ carbon dioxide in air. At confluence, the medium was changed and supplemented with $8 \mu \mathrm{g} / \mathrm{ml}$ biotin and $4 \mu \mathrm{g} / \mathrm{ml}$ pantothenic acid for 2 days. Differentiation was initiated by the addition of $10 \mu \mathrm{g} / \mathrm{ml}$ insulin and $0.4 \mu \mathrm{g} / \mathrm{ml}$ dexamethasone (day 0, 2 days after confluence). After 48 hours (day 2), the medium was changed to DMEM supplemented with $8 \mu \mathrm{g} / \mathrm{ml}$ biotin, $4 \mu \mathrm{g} / \mathrm{ml}$ pantothenic acid, and $10 \mu \mathrm{g} / \mathrm{ml}$ insulin. Subsequently, the medium was replaced every 48 hours with DMEM containing $8 \mu \mathrm{g} / \mathrm{ml}$ biotin, $4 \mu \mathrm{g} / \mathrm{ml}$ pantothenic acid, and $0.2 \mu \mathrm{g} / \mathrm{ml}$ insulin. Adipocyte differentiation was examined microscopically. RNA was isolated (RNeasy Kit; QIAGEN) every 2 days starting at 50\% confluence and ending 8 days after initiation of differentiation (day 8).

Isolation of mature adipocytes from mouse epididymal fat pads. Fat pads were removed surgically, weighed, minced with scissors, and washed in KrebsRinger buffer plus HEPES (KRBH) $\left(120 \mathrm{mM} \mathrm{NaCl}, 4 \mathrm{mM} \mathrm{KH}_{2} \mathrm{PO}_{4}, 700 \mu \mathrm{M}\right.$ $\mathrm{MgSO}_{4}, 10 \mathrm{mM} \mathrm{NaHCO}, 1 \mathrm{mM} \mathrm{CaCl} 2,30 \mathrm{mM}$ HEPES, $200 \mathrm{nM}$ adenosine, $1 \% \mathrm{BSA}, \mathrm{pH} 7.4)$ at $37^{\circ} \mathrm{C}$. Collagenase digestion was performed as described previously (33). Per $100 \mathrm{mg}$ of AT, $400 \mu \mathrm{l} \mathrm{KRBH}$ and $25 \mu \mathrm{l}$ collagenase A (20 $\mathrm{mg} / \mathrm{ml}$; Roche Diagnostics) were added, and the mixture was incubated in a shaking water bath at $37^{\circ} \mathrm{C}$ for 1 hour. After collagenase digestion and the addition of $250 \mu \mathrm{l}$ of $\mathrm{KRBH}$ at $37^{\circ} \mathrm{C}$, the cells were mixed and gently passed through a $250-\mu \mathrm{m}$ nylon mesh filter. The cells were washed twice with $750 \mu \mathrm{KRBH}$ at $37^{\circ} \mathrm{C}$ and briefly centrifuged at $200 \mathrm{~g}$. Adipose cells floating on top of the aqueous buffer were collected. Total RNA was isolated using an RNeasy Kit (QIAGEN).

Plasma lipids and AT fatty acid analysis. Blood was collected from fed animals by retroorbital bleeding, and EDTA-plasma was prepared. Plasma TG concentrations (GPO-Trinder 20) and HDL cholesterol concentrations (HDLCholesterol Kit 352-3) were measured enzymatically (Sigma-Aldrich).

The fatty acid composition of PLs and TGs in AT of L2 and LO-MCK mice was determined by GC-MS analysis from AT of $4 L 2$ and $4 L O-M C K$ mice. Fat pads of fed mice were removed surgically, weighed, and homogenized in PBS in sterile plastic vials. Immediately afterward, the homogenate was transferred to glass vials with Teflon stoppers. Lipids were extracted with $5 \mathrm{ml}$ of chloroform/methanol (2:1, vol/vol) on ice, the organic phase was collected, and the aqueous phase was reextracted with $3 \mathrm{ml}$ chloroform/methanol (2:1, $\mathrm{vol} / \mathrm{vol})$. The organic phases were pooled and dried under nitrogen. Per 100 $\mathrm{mg}$ of AT, $1 \mathrm{ml}$ of chloroform was added, and $100 \mu \mathrm{l}$ of the redissolved lipids were separated by thin-layer chromatography (silica gel 60; hexane/diethyl ether/acetic acid, 70:29:1). PL- and TG-specific spots were scraped from the plates and dissolved in $500 \mu \mathrm{l}$ toluene containing $30 \mu \mathrm{g}$ 15:0 fatty acid as

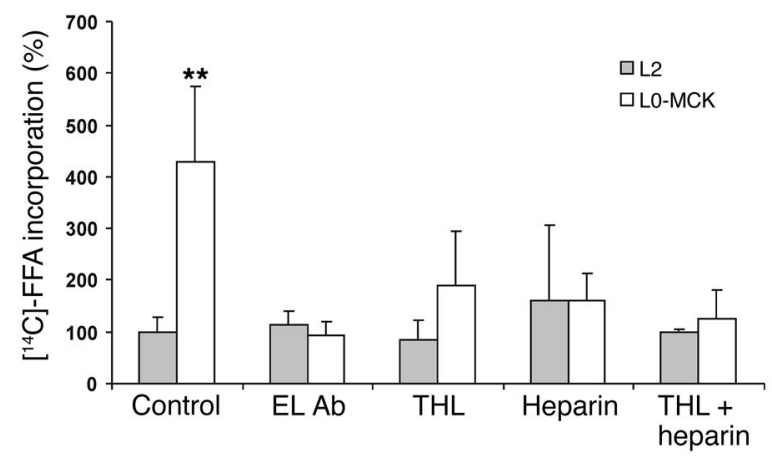

\section{Figure 5}

Uptake and incorporation of PL-derived FFAs by AT. Fat pads of mice in the presence (L2) or absence ( $L O-M C K)$ of LPL were incubated with DMEM/10\% lipoprotein-deficient serum (LPDS) containing $\left[{ }^{14} \mathrm{C}\right] \mathrm{PC}$-labeled HDL (50 $\mu \mathrm{g} \mathrm{HDL}$-associated protein/sample) at $37^{\circ} \mathrm{C}$ for 6 hours. The incorporation of FFAs into the TG moiety of AT was performed in the absence (control) or presence of $50 \mu \mathrm{g}$ anti-EL $\mathrm{IgG}, 50 \mu \mathrm{g} / \mathrm{ml} \mathrm{THL}$ or/and $2 \mathrm{U} / \mathrm{ml}$ heparin in a total volume of $150 \mu \mathrm{l}$. Results are mean \pm SD from 5 mice of each genotype performed in duplicate. ${ }^{* *} P \leq 0.01$. 


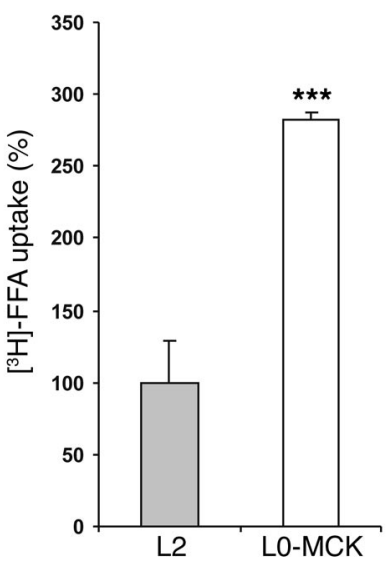

Figure 6

Uptake and incorporation of albumin-bound FFAs by AT. Fat pads of mice in the presence (L2) or absence ( $L O-M C K)$ of $L P L$ were incubated with DMEM $/ 1 \%$ FFA-free BSA $/ 200 \mu \mathrm{M}$ oleate/[$\left.{ }^{3} \mathrm{H}\right]$ oleate $(5 \mu \mathrm{Ci} / \mathrm{ml})$ at $37^{\circ} \mathrm{C}$ for 6 hours. Results are mean \pm SD from 3 mice of each genotype performed in triplicate. ${ }^{* *} P \leq 0.001$.

internal standard. Transesterification and gas chromatographic analysis were performed according to the method of Sattler et al. (34).

$R N A$ isolation and Northern blot analysis. Fat pads of adult $L 2$ and LO-MCK mice were removed surgically, weighed, and subsequently frozen in liquid nitrogen. Total RNA was isolated using the TRI Reagent procedure according to the manufacturer's protocol (Molecular Research Center Inc.). For Northern blot analysis, $10 \mu \mathrm{g}$ of total RNA was separated by $1 \%$ formaldehyde/agarose gel electrophoresis and blotted overnight onto nylon membranes (Hybond $\mathrm{N}^{+}$; Amersham Biosciences). RNA was immobilized to membranes by ultraviolet irradiation. The blots were prehybridized for 4 hours at $65^{\circ} \mathrm{C}$ in a buffer containing $0.15 \mathrm{M}$ sodium phosphate (pH 7.2), 1 mM EDTA, 7\% (wt/vol) SDS, and 1\% (wt/vol) BSA. Membranes were hybridized in the same buffer at $65^{\circ} \mathrm{C}$ overnight with appropriate radiolabeled murine EL and LPL probes. After hybridization, the blots were washed in $\times 2$ SSC (SSC: $0.15 \mathrm{M} \mathrm{NaCl}, 0.015 \mathrm{M}$ sodium citrate) containing $0.1 \%$ SDS for 20 minutes at room temperature, followed by 2 additional washing steps in $\times 1 \mathrm{SSC} / 0.1 \%$ SDS for 10 minutes at $65^{\circ} \mathrm{C}$ each. Specific hybridization signals were visualized after exposure to PhosphorImager Screens on a Storm PhosphorImager and analyzed using ImageQuant software (Amersham Biosciences).

A full-length murine EL cDNA clone was generated from total mouse liver RNA by RT-PCR. After reverse transcription of liver mRNA using oligo-dT primers, the resulting cDNA was PCR amplified with 2 EL-specific primers - 5'-AAGGATGCGAAACACGGTTT-3' (forward) and 5'-GGCCAAGTTCACAAAGGGAC-3' (reverse) - using the Advantage RT-for-PCR Kit (BD Biosciences - Clontech). The reaction resulted in a 1.5-kb EL cDNA fragment, which was subcloned into pBluescript. After we confirmed the correct amplification product by DNA sequencing, an 800bp BamHI-XhoI fragment was radioactively labeled with [ $\left.{ }^{32} \mathrm{P}\right] \mathrm{dCTP}$ (NEN, PerkinElmer Life and Analytical Sciences; Prime-a-Gene Kit, Promega Corp.) and used to detect murine EL mRNA in Northern blot experiments. To detect murine $L P L$ mRNA, we used a 700-bp PstI fragment from exon 10 of mouse LPL as a probe.

Real-time PCR. RT-PCR and quantitative real-time PCR were performed according to the manufacturer's instructions (TaqMan One-Step RT-PCR Kit; Applied Biosystems) on a 5700 ABI PRISM Sequence Detection System instrument $(35,36)$. Murine EL and $\beta$-actin TaqMan primers and probes were designed using Primer Express software version 2.0 (Applied Biosystems). Primers and probes were: EL forward: 5'-TCCTGCATACCTACACGCTGTC-3', EL reverse: 5'-GTCAATGTGACCCACAGGCA-3', EL probe: $5^{\prime}$-CCGAATCCCAATGCTAAGCCAAA-3'; $\beta$-actin forward: $5^{\prime}$ GACAGGATGCAGAAGGAGATTACTG- $3^{\prime}, \beta$-actin reverse: $5^{\prime}$-GCCACCGATCCACACAGAGT-3', $\beta$-actin probe: 5 '-CAAGATCATTGCTCCTCCTGAGCGCA-3'. Sequence-specific EL amplification was detected by an increasing fluorescence signal of FAM (reporter dye) during the amplification cycles. Amplification of $\beta$-actin was performed on all samples as an internal control for variations in mRNA amounts. Levels of the different mRNA amounts were normalized to $\beta$-actin mRNA levels.

Tissue lipase assays. AT, SM, and CM from mice were excised, weighed, and minced with scissors. For assay of the LPL activity, the tissue samples were transferred to ice-cold tubes containing $1 \mathrm{ml}$ of DMEM, 2\% BSA (wt/vol), and $2 \mathrm{U} / \mathrm{ml}$ of heparin and incubated at $37^{\circ} \mathrm{C}$ for 1 hour. LPL activity was assayed as described previously (37). PL activity was assayed in a mixture of $1 \mu \mathrm{Ci}\left[{ }^{14} \mathrm{C}\right]$ dipalmitoyl-PC (NEN; PerkinElmer Life and Analytical Sciences) and $13.3 \mu$ l lecithin $(1 \mathrm{mg} / \mathrm{ml})$ in $50 \mu \mathrm{l}$ substrate buffer Tris-TCNB $(100 \mathrm{mM}$ Tris- $\mathrm{HCl}$ pH 7.4, 1\% Triton X-100, $5 \mathrm{mM} \mathrm{CaCl}_{2}, 200 \mathrm{mM} \mathrm{NaCl}$, 0.1\% FFAfree BSA). This mixture, termed the PC substrate, was vortexed for 2 minutes and then evaporated under a stream of nitrogen. The dried PL was redissolved in $500 \mu \mathrm{l}$ Tris-TCNB and vortexed for 10 seconds. Cell extracts from AT (in $250 \mu \mathrm{l}$ DMEM, $2 \% \mathrm{BSA}, 2 \mathrm{U} / \mathrm{ml}$ of heparin) were incubated at $37^{\circ} \mathrm{C}$ for 1 hour. To inhibit EL enzyme activity, we incubated AT cell extracts with $50 \mu \mathrm{g}$ anti-EL IgG for 1 hour at $4^{\circ} \mathrm{C}(28)$. Subsequently, the conditioned media were incubated with $10 \mu \mathrm{l}$ substrate at $37^{\circ} \mathrm{C}$ for 1 hour. The reactions were terminated by addition of $25 \mu \mathrm{l} \mathrm{N} \mathrm{HCl}$, and lipids were extracted with $1 \mathrm{ml}$ hexane/isopropanol (3:2, vol/vol; 0.1\% $\mathrm{HCl}$ ). Five hundred microliters of the upper phase were dried and reconstituted in 100 $\mu \mathrm{l}$ hexane/isopropanol $(3: 2, \mathrm{vol} / \mathrm{vol})$. After separation by thin-layer chromatography (hexane/diethyl ether/acetic acid, 70:29:1), the liberated $\left[{ }^{14} \mathrm{C}\right] \mathrm{FFAs}$ were quantitated by scintillation counting.

HDL labeling with $\left[{ }^{14} \mathrm{C}\right] P C$. HDL was isolated by ultracentrifugation in an SW41 rotor (38). The protein concentration was determined by a Protein Assay Kit (Bio-Rad Laboratories). Labeling of HDL was performed with 4 $\mu \mathrm{Ci}\left[{ }^{14} \mathrm{C}\right]$ dipalmitoyl-PC labeled in the sn- 1 and sn-2 positions. $\left[{ }^{14} \mathrm{C}\right] \mathrm{PC}$ was dried under a gentle stream of nitrogen. After the addition of $4 \mathrm{mg}$ HDLassociated protein $/ \mathrm{ml}$, the mixture was overlaid with argon and incubated overnight at $37^{\circ} \mathrm{C}$ under continuous shaking. Labeled HDL was separated from unincorporated $\left[{ }^{14} \mathrm{C}\right] \mathrm{PC}$ and desalted by exclusion chromatography on PD-10 columns (Amersham Biosciences) using PBS as eluent.

Incubation of isolated fat pads with $\left[{ }^{14} \mathrm{C}\right] P C$-labeled $H D L$. Fat pads were removed surgically, washed with DMEM, and incubated with $\left[{ }^{14} \mathrm{C}\right]$ dipalmitoyl-PC labeled HDL (50 $\mu \mathrm{g}$ HDL-associated protein/sample) in DMEM containing $10 \%$ lipoprotein-deficient serum (LPDS). To inhibit EL enzyme activity, we preincubated fat pads with $50 \mu \mathrm{g}$ EL antibody for 1 hour at $4^{\circ} \mathrm{C}$. To inhibit enzyme activity of both EL and LPL, we preincubated fat pads with $50 \mu \mathrm{g} / \mathrm{ml}$ of the lipase inhibitor THL (25) for 1 hour either in the absence or in the presence of $2 \mathrm{U} / \mathrm{ml}$ heparin. All incubations were performed in a total volume of $150 \mu \mathrm{l}$ at $37^{\circ} \mathrm{C}$ for 6 hours. Subsequently, the fat pads were washed twice with PBS, dried, and weighed, and the lipids were extracted with $3 \mathrm{ml}$ chloroform/methanol (2:1, vol/vol) on a rotary shaker for 30 minutes. The fat pads were removed, and the liquid was evaporated under a stream of nitrogen. The lipids were redissolved in $100 \mu \mathrm{l}$ of chloroform and separated by thin-layer chromatography (hexane/diethyl ether/acetic acid, 70:29:1). The TG-specific spots were excised, and the incorporated $\left[{ }^{14} \mathrm{C}\right] \mathrm{FFAs}$ were quantitated by scintillation counting.

Incubation of isolated fat pads with $\left[{ }^{3} H\right] F F A s$. Fat pads were removed surgically, weighed, washed with DMEM, and incubated with $5 \mu \mathrm{Ci}\left[{ }^{3} \mathrm{H}\right]$ oleate (NEN; PerkinElmer Life and Analytical Sciences) and $200 \mu \mathrm{M}$ nonradioactive oleate 
in DMEM containing $1 \%$ FFA-free BSA for 6 hours at $37^{\circ} \mathrm{C}$. After incubation, the fat pads were washed twice in PBS and dried, and the lipids were extracted with $1 \mathrm{ml}$ chloroform/methanol $(2: 1, \mathrm{vol} / \mathrm{vol})$ on a rotary shaker for $30 \mathrm{~min}$ utes. After evaporation of the solvent under a stream of nitrogen, lipids were redissolved in $100 \mu \mathrm{l}$ chloroform and separated by thin-layer chromatography (hexane/diethyl ether/acetic acid, 70:29:1). The TG-specific spots were excised, and the incorporated $\left[{ }^{3} \mathrm{H}\right]$ FFAs were quantitated by scintillation counting.

Statistics. Results are expressed as mean \pm SD. Two-tailed Student's $t$ test was used to calculate statistical significance among groups. Differences at $P<0.05$ were considered to be statistically significant.

\section{Acknowledgments}

This work was supported by the Austrian Fonds zur Förderung der Wissenschaftlichen Forschung (Spezialforschungsbereich Biomembranes F00701 and F00713) and by the Austrian Federal Min- istry of Education, Science, and Culture (Genomforschung Austria Project G.O.L.D., Genomics of Lipid-Associated Disorders). The authors thank J.D. Brunzell (Seattle, Washington, USA) for the 5D2 antibody, R. Schreiber and H. Reicher for excellent technical assistance, and A. Hermann for her invaluable help with mice care.

Received for publication May 21, 2002, and accepted in revised form November 9, 2004.

Address correspondence to: Rudolf Zechner, Institute of Molecular Biosciences, University of Graz, Heinrichstrabe 31a, A-8010 Graz, Austria. Phone: 43-316-3801900; Fax: 43-316-3809016; E-mail: rudolf.zechner@uni-graz.at.

Elke M. Wagner's present address is: NIH, Bethesda, Maryland, USA.
1. Goldberg, I.J. 1996. Lipoprotein lipase and lipolysis: central roles in lipoprotein metabolism and atherogenesis. J. Lipid Res. 37:693-707.

2. Zechner, R. 1997. The tissue-specific expression of lipoprotein lipase: implications for energy and lipoprotein metabolism. Curr. Opin. Lipidol. 8:77-88.

3. Murthy, V., Julien, P., and Gagne, C. 1996. Molecular pathobiology of the human lipoprotein lipase gene. Pharmacol. Ther. 70:101-135.

4. Ginzinger, D.G., et al. 1999. Lipid and lipoprotein analysis of cats with lipoprotein lipase deficiency. Eur. J. Clin. Invest. 29:17-26.

5. Savonen, R., et al. 1999. Chylomicron metabolism in an animal model for hyperlipoproteinemia type I. J. Lipid Res. 40:1336-1346.

6. Santamarina-Fojo, S. 1992. Genetic dyslipoproteinemias: role of lipoprotein lipase and apolipoprotein C-II. Curr. Opin. Lipidol. 3:186-195.

7. Weinstock, P.H., et al. 1995. Severe hypertriglyceridemia, reduced high density lipoprotein, and neonatal death in lipoprotein lipase knockout mice. Mild hypertriglyceridemia with impaired very low density lipoprotein clearance in heterozygotes. J. Clin. Invest. 96:2555-2568.

8. Coleman, T., et al. 1995. COOH-terminal disruption of lipoprotein lipase in mice is lethal in homozygotes, but heterozygotes have elevated triglycerides and impaired enzyme activity. J. Biol. Chem. 270:12518-12525.

9. Paterniti, J.R., Jr., Brown, W.V., Ginsberg, H.N., and Artzt, K. 1983. Combined lipase deficiency (cld): a lethal mutation on chromosome 17 of the mouse. Science. 221:167-169.

10. Strauss, J.G., et al. 2001. Adenovirus-mediated rescue of lipoprotein lipase-deficient mice. Lipolysis of triglyceride-rich lipoproteins is essential for high density lipoprotein maturation in mice. J. Biol. Chem. 276:36083-36090.

11. Levak-Frank, S., et al. 1997. Induced mutant mice expressing lipoprotein lipase exclusively in muscle have subnormal triglycerides yet reduced high density lipoprotein cholesterol levels in plasma. J. Biol. Chem. 272:17182-17190.

12. Weinstock, P.H., et al. 1997. Lipoprotein lipase controls fatty acid entry into adipose tissue, but fat mass is preserved by endogenous synthesis in mice deficient in adipose tissue lipoprotein lipase. Proc. Natl. Acad. Sci. U. S. A. 94:10261-10266.

13. Levak-Frank, S., et al. 1999. Induced mutant mouse lines that express lipoprotein lipase in cardiac mus- cle, but not in skeletal muscle and adipose tissue, have normal plasma triglyceride and high-density lipoprotein-cholesterol levels. Proc. Natl. Acad. Sci. U. S. A. 96:3165-3170.

14. Merkel, M., et al. 1998. Lipoprotein lipase expression exclusively in liver. A mouse model for metabolism in the neonatal period and during cachexia. J. Clin. Invest. 102:893-901.

15. Brun, L.D., et al. 1989. Familial lipoprotein lipaseactivity deficiency: study of total body fatness and subcutaneous fat tissue distribution. Metabolism. 38:1005-1009.

16. Julien, P., Despres, J.P., and Angel, A. 1989. Scanning electron microscopy of very small fat cells and mature fat cells in human obesity. J. Lipid Res. 30:293-299.

17. Peeva, E., et al. 1992. Adipose cell size and distribution in familial lipoprotein lipase deficiency. Int. J. Obes. Relat. Metab. Disord. 16:737-744.

18. Ullrich, N.F., Purnell, J.Q., and Brunzell, J.D. 2001. Adipose tissue fatty acid composition in humans with lipoprotein lipase deficiency. J. Investig. Med. 49:273-275.

19. Wagner, E.M., et al. 2004. Defective uptake of triglyceride-associated fatty acids in adipose tissue causes the SREBP-1c-mediated induction of lipogenesis. J. Lipid Res. 45:356-365.

20. Hirata, K., et al. 1999. Cloning of a unique lipase from endothelial cells extends the lipase gene family. J. Biol. Chem. 274:14170-14175.

21. Jaye, M., et al. 1999. A novel endothelial-derived lipase that modulates HDL metabolism. Nat. Genet. 21:424-428.

22. Bensadoun, A., and Berryman, D.E. 1996. Genetics and molecular biology of hepatic lipase. Curr. Opin. Lipidol. 7:77-81.

23. Fuki, I.V., et al. 2003. Endogenously produced endothelial lipase enhances binding and cellular processing of plasma lipoproteins via heparan sulfate proteoglycan-mediated pathway. J. Biol. Chem. 278:34331-34338.

24. Strauss, J.G., Hayn, M., Zechner, R., Levak-Frank, S., and Frank, S. 2003. Fatty acids liberated from HDL-phospholipids by endothelial derived lipase are incorporated into lipids in HepG2 cells. Biochem. J. 371:981-988.

25. Strauss, J.G., et al. 2002. Endothelial cell-derived lipase mediates uptake and binding of high- density lipoprotein (HDL) particles and the selective uptake of HDL- associated cholesterol esters independent of its enzymic activity. Biochem. J. 368:69-79.
26. Broedl, U.C., Maugeais, C., Marchadier, D., Glick, J.M., and Rader, D.J. 2003. Effects of nonlipolytic ligand function of endothelial lipase on high density lipoprotein metabolism in vivo. J. Biol. Chem. 278:40688-40693.

27. McCoy, M.G., et al. 2002. Characterization of the lipolytic activity of endothelial lipase. J. Lipid Res. 43:921-929.

28. Jin, W., Millar,J.S., Broedl, U., Glick, J.M., and Rader, D.J. 2003. Inhibition of endothelial lipase causes increased HDL cholesterol levels in vivo. J. Clin. Invest. 111:357-362. doi:10.1172/JCI200316146.

29. Ma, K., et al. 2003. Endothelial lipase is a major genetic determinant for high-density lipoprotein concentration, structure, and metabolism. Proc. Natl. Acad. Sci. U. S. A. 100:2748-2753.

30. Maugeais, C., et al. 2003. Dose-dependent acceleration of high-density lipoprotein catabolism by endothelial lipase. Circulation. 108:2121-2126.

31. Ishida, T., et al. 2003. Endothelial lipase is a major determinant of HDL level.J. Clin. Invest. 111:347-355. doi:10.1172/JCI200316306.

32. Levak-Frank, S., et al. 1995. Muscle-specific overexpression of lipoprotein lipase causes a severe myopathy characterized by proliferation of mitochondria and peroxisomes in transgenic mice. J. Clin. Invest. 96:976-986.

33. Rodbell, M. 1964. Metabolism of isolated fat cells: effects of hormones on glucose metabolism and lipolysis. J. Biol. Chem. 239:375-380.

34. Sattler, W., Puhl, H., Hayn, M., Kostner, G.M., and Esterbauer, H. 1991. Determination of fatty acids in the main lipoprotein classes by capillary gas chromatography: BF3/methanol transesterification of lyophilized samples instead of Folch extraction gives higher yields. Anal. Biochem. 198:184-190.

35. Lie, Y.S., and Petropoulos, C.J. 1998. Advances in quantitative PCR technology: $5^{\prime}$ nuclease assays. Curr. Opin. Biotechnol. 9:43-48.

36. Orlando, C., Pinzani, P., and Pazzagli, M. 1998. Developments in quantitative PCR. Clin. Chem. Lab. Med. 36:255-269.

37. Kratky, D., Strauss, J.G., and Zechner, R. 2001. Tissue-specific activity of lipoprotein lipase in skeletal muscle regulates the expression of uncoupling protein 3 in transgenic mouse models. Biochem. J. 355:647-652

38. Puhl, H., Waeg, G., and Esterbauer, H. 1994. Methods to determine oxidation of low-density lipoproteins. Methods Enzymol. 233:425-441. 